\title{
O ADVOGADO E OS “TRABALHADORES FAVELADOS": ANTOINE DE MAGARINOS TORRES E A PRÁTICA POLÍTICA NAS FAVELAS CARIOCAS DOS ANOS 1950 E 1960
}

The lawyer and the "slums' workers": Antoine de Magarinos Torres and the political practice in Rio's slums in the 1950s and 1960s

\section{MAURO AMOROSO E RAFAEL SOARES GONÇALVES}

\footnotetext{
Mauro Amoroso é mestre em História pela Universidade Federal Fluminense, doutor em História pela Fundação Getulio Vargas e professor da Faculdade de Educação da Baixada Fluminense da Universidade do Estado do Rio de Janeiro, (amoroso. mauro@gmail.com).

Rafael Soares Gonçalves é mestre em Dynamiques comparées des sociétés en développement, doutor em Histoire et civilisations pela Université Paris-Diderot e professor do Departamento de Serviço Social da Pontifícia Universidade Católica do Rio de Janeiro, (rafaelsgoncalves@yahoo.com.br).

Artigo recebido em 18 de julho e aprovado para publicação em 3 de outubro de 2016.
} 


\title{
RESUMO
}

Este artigo pretende analisar a trajetória do advogado Antoine de Magarinos Torres, ator político de relevante atuação nas favelas do Rio de Janeiro nos anos 1950 e 1960. Tendo como base principal a favela do Borel, foi um dos criadores da União dos Trabalhadores Favelados (UTF), entidade original por pretender reunir associações de moradores de diferentes favelas. Através de sua trajetória e de sua prática política, é possível analisar os conflitos, os diferentes interesses e os atores que implementaram distintos projetos políticos e formas de intervenção nesses espaços, objeto central de nossa reflexão.

Palavras-CHAVE: Antoine de Magarinos Torres; União dos Trabalhadores Favelados; favelas; Rio de Janeiro; direito à cidade.

\begin{abstract}
This article analyzes the trajectory of the lawyer Antoine de Magarinos Torres, a political actor who had a significant activity in the slums of Rio de Janeiro in the 1950's and 1960's. Having as a main base of operations the slum of Borel, he was one of the creators of the Slums Workers Union, an original entity as it intended to gather residents' associations from different slums. Through its story and political practice, it is possible to analyze the conflicts, different interests and actors that have implemented different political projects and forms of intervention in these spaces, which are the central object of our reflection.
\end{abstract}

KeYwords: Antoine de Magarinos Torres; Slums Workers Union; slums; Rio de Janeiro; right to the city.

\section{RÉSUMÉ}

Cet article analyse la trajectoire de l'avocat Antoine de Magarinos Torres, acteur politique qui a joué un rôle important dans les bidonvilles de Rio de Janeiro aux années 1950 et 1960. Ayant le bidonville du Borel comme principale base d'opération, il a été un des créateurs de l'Union des Travailleurs des Bidonvilles, une entité originale puisque destinée à réunir les associations de résidents de différents bidonvilles. En suivant son histoire et sa pratique politique, il est possible d'analyser les conflits, les différents intérêts et les acteurs qui ont mis en œuvre des différents projets politiques et modes d'intervention dans ces espaces, objet central de notre réflexion.

Mots-CLÉs: Antoine de Magarinos Torres; Union des Travailleurs des Bidonvilles; bidonvilles; Rio de Janeiro; droit à la ville. 
ntoine de Magarinos Torres é uma rica fonte para o entendimento da mobilização política nas favelas cariocas na década de 1950, bem como das disputas e contradições envolvendo tal campo. Filho de desembargador, morador do bairro da Usina, o advogado exerceu uma forte militância política em órgãos de tendência comunista desde o início da década de 1950, e em 1954 foi um dos fundadores e principais articuladores, no Morro do Borel, ${ }^{1}$ da União dos Trabalhadores Favelados (UTF). ${ }^{2}$ Existe no Borel uma memória consolidada sobre esse personagem, caracterizada pela sua mitificação. ${ }^{3}$ A forma como ele é descrito por Manoel Gomes ${ }^{4}$ em seu livro de memórias sobre o movimento associativo do Borel revela a reverência com a qual é tratado: " (...) que morava no Rodo da Usina e chamava-se Doutor Antoine de Magarinos Torres (a quem pedimos os mais respeitosos sentimentos por sua coragem, denodo e bravura)" (Gomes, 1980: 16). Já outras fontes, conforme será explorado posteriormente, apresentam esse personagem histórico com cores consideravelmente mais críticas.

Há poucos estudos aprofundados sobre Magarinos Torres. Retomar sua história é fundamental para o entendimento das favelas como campo para a implementação de projetos políticos e local de batalha de significados ligados à percepção simbólica desses espaços perante a sociedade carioca nas décadas de 1950 e 1960. A releitura desse período através de sua figura se insere em um grande esforço da literatura para compreender as mobilizações políticas nas favelas em um momento crucial da luta por direitos da classe trabalhadora carioca (Lima, 1987; Fischer, 2008; Gonçalves, 2013; Pestana, 2014; Oliveira, 2014 e Amoroso, 2015). 0 objetivo do presente artigo é analisar as propostas políticas de intervenção em favelas do advogado, a partir de sua trajetória política e pessoal, bem como de organização do movimento associativo desses espaços, e os significados construídos a partir da memória sobre sua presença à frente da UTF a partir de sua atuação, principalmente, nas favelas do Borel e Parque União.

\section{O PROCESSO DE MITIFICAÇÃO: A CONSTRUÇÃO SIMBÓLICA DO "DEFENSOR DAS FAVELAS"}

ntoine de Magarinos Torres nasceu no Rio de Janeiro em 1916, filho de Antônio Eu-
gênio de Magarinos Torres e da francesa Victorine Marie Jeanine Planchon Magarinos Torres (Fundo de Polícia Política da Guanabara/APERJ, prontuário 47. 727, folha 1). Seu pai 
foi um reconhecido jurista, autor do modelo de nota promissória até hoje adotado no Brasil, desembargador e presidente do Tribunal do Júri durante dez anos. A trajetória profissional do filho é descrita como a postura de "abraçar como um Hércules a causa dos humildes moradores do Borel" (Gomes, 1980: 16). A menção ao herói mitológico serve como exemplo para dar cores à imagem mitificada e hagiográfica que esse discurso específico de memória constrói sobre o advogado. Assim, a forma como sua figura é construída em diferentes depoimentos revela um esforço discursivo para a constituição do que Raoul Girardet (1987) chama de 0 mito do salvador, ou seja, uma representação possuidora de grande magnitude dentro do imaginário político, ainda mais quando se refere a um indivíduo que atuou num intervalo de tempo relativamente curto.

Desse modo, é possível identificar um processo de consolidação da narrativa mistificadora da figura de Magarinos Torres como um autêntico herói, que resolveu "abraçar a causa" dos moradores do Borel, conforme o depoimento, por exemplo, de um antigo morador (Chico da Lapa, 15/02/2011):

Ele [Magarinos Torres] era muito querido. Morreu cedo talvez porque se preocupou muito. Era uma criatura fantástica. Não tinha grandes coisas de confusão, não, quando tinha que tirar tirava tudo. Eles [policiais] não queriam que construísse [sobre moradores construindo barracões na favela], mas quando a pessoa já estava morando não tinha jeito. 0 pessoal construía em um dia e no outro já estava morando. (...) O Magarinos pra mim foi uma grande criatura, largava as coisas dele e vinha pra cá ajudar.

Nesse relato, Magarinos é visto como um defensor dos moradores do Borel, capaz de se dedicar à sua causa a ponto de "largar as coisas dele e vir pra cá ajudar". Ou seja, com um ator cujo objetivo, a defesa dos moradores do Borel, orienta sua existência, dentro de uma narrativa coesa e elogiosa própria dessa forma de relato biográfico. Desse modo, sua existência passaria a obedecer a uma cronologia lógica, permeada por um princípio e objetivo de ação, a luta em prol dos favelados. A construção de sua imagem, inserida no quadro de disputas pela posse da terra pelo qual passaram a favela do Borel e seus moradores a partir dos anos 1950, é feita de forma a apresentar "a brusca irrupção de um Salvador à frente do poder, de um herói que capta em torno dele todos os fervores da esperança coletiva" (Girardet, 1987: 66).

A UTF teria se iniciado sob a inspiração de Magarinos Torres após este ter sido contatado pelos moradores do Morro do Borel para defendê-los de um processo de despejo movido pela empresa Borel Meuren, que queria lotear as terras onde se encontrava a favela. Apesar de a UTF ser uma entidade cujos membros gozavam de certa autonomia, é possível observar, através dos relatos de suas primeiras reuniões, a forte ascendência de Magarinos Torres sobre os rumos da associação, pela qual foi, aliás, agraciado com a carteira oo 1. 
APERJ, Fundo POLPOL, Prontuário GB no47.727

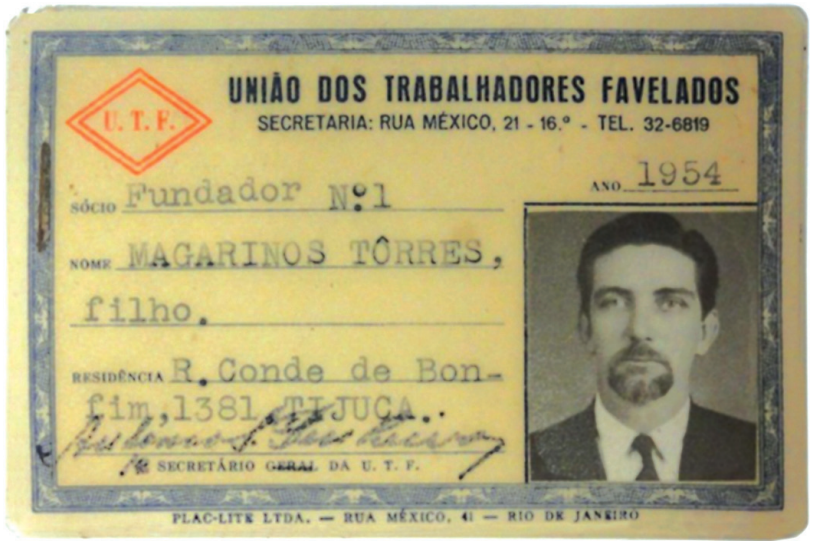

Os elementos presentes nas narrativas citadas sobre o advogado reforçam uma visão mítica a seu respeito, devendo-se atentar, mais uma vez, para o fato de que o mito possui a função de selecionar fatos do passado a fim de torná-los inteligíveis, visando a sua transmissão para gerações futuras e estabelecendo uma ligação com certos ritos de origem, moralidade e conduta (Finley, 1989). Esse é um dos aspectos que embasam a construção mítica da imagem de Magarinos Torres, segundo o discurso de Manoel Gomes, ${ }^{5}$ como o homem providencial, a figura de chefe ou guia que consolidaria representações de emoção, esperança e adesão, constituindo um "personagem símbolo" que "através de um e de outro exprime uma visão coerente e completa do destino coletivo" (Girardet, 1987: 70).

\section{Magarinos TORRES E SUA ATUAÇÃo naS DEMAIS FAVELAS CARIOCAS}

$\mathrm{O}$

PCB vinha tendo forte presença no cenário político local no pós-guerra. As células comunistas tinham uma presença nos bairros, assim como posteriormente uma série de outras estruturas, como os comitês democráticos, as uniões femininas e os comitês pela paz. Paulo Fontes, a partir do caso de São Paulo, analisa que foi no imediato pós-Segunda Guerra Mundial que começaram a proliferar organizações de moradores que tinham como principal referência o território específico de um bairro (Fontes, 2013: 76). Negro e Silva (2003: 55) afirmam que os "comunistas revelaram grande agilidade na organização de dezenas de Comitês Populares e Democráticos, que se envolviam em problemas dos bairros e discutiam temas como habitação, custos dos gêneros de primeira necessidade, instrução e saúde pública, lazer, etc." 
A compreensão da forma de intervenção urbana do PCB é importante para entender melhor a atuação de Magarinos Torres e da própria UTF. Apesar de não termos encontrado registros que comprovem a filiação de Magarinos ao PCB, é notória a sua proximidade com 0 Partido Comunista. Magarinos Torres foi um importante membro do movimento dos Juristas pela Paz ${ }^{6}$ e chegou a coordenar o Comitê Carioca dos Partidários da Paz, entidades ligadas ao PCB.

Essas experiências certamente tiveram forte influência na estratégia de organização da UTF. Apesar da existência de associações de moradores em muitas favelas, não existia uma estrutura associativa capaz de congregar e federar o conjunto dos movimentos representativos dos favelados na esfera da cidade. Para mediar tal questão, a UTF procurou ampliar suas atividades, estabelecendo núcleos em várias favelas. Inserindo-se nas questões locais, a entidade transformou-se na primeira experiência de estrutura supralocal de favelados que aspirava a congregar todos os moradores dessas áreas da cidade (Lima, 1989: 105). Magarinos Torres ressaltou em um de seus primeiros discursos para os moradores do Borel, segundo as palavras de Manoel Gomes, a necessidade de consolidar o associativismo como a via capaz de assegurar o direito à permanência através da necessidade de " $1 \underline{0}$ - manter-se organizado dentro da associação local; $2^{\circ}$ - estender a união dos favelados em todo 0 âmbito territorial do Rio de Janeiro, onde quer que haja favela" (Gomes, 1980: 24). Essa estratégia de traçar uma solidariedade inter favelas se manifestou, por exemplo, através de uma das condições estabelecidas pela UTF, em 1954, para todas as famílias desejosas de se estabelecer na Favela do Borel: terem sido expulsas da Favela de Santo Antônio, ${ }^{7}$ que estava sofrendo um processo de despejo.

Da mesma forma, os diferentes centros da UTF, disseminados em algumas favelas, esforçavam-se para representar diretamente os favelados junto aos poderes públicos, desempenhando por vezes o papel de associação de moradores. Se bem que a UTF se tenha declarado independente de qualquer partido político, o apoio comunista provou ser, de fato, fundamental para suas atividades, como demonstra a extensiva cobertura dada pelo jornal comunista Imprensa Popular às suas iniciativas. ${ }^{8}$ A preocupação da imprensa com a UTF, ${ }^{9}$ e muito especialmente com seu fundador, chamou prontamente a atenção das elites e provocou temores de uma possível manipulação política dos favelados.

Pela sua formação jurídica, Magarinos Torres procurou traduzir a mobilização política em instrumentos jurídicos dentro de um esforço de construção de direitos. Sua atuação se inseriu em uma linha de advogados, de diferentes linhas políticas e formas de atuação, que procuraram traduzir em termos jurídicos mobilizações políticas dos favelados. Esse era o caso, por exemplo, de Geraldo Moreira, muito atuante na favela do Jacarezinho e que chegou a ser eleito vereador do Distrito Federal. 
Magarinos Torres elaborou em 1954, no âmbito da UTF, um anteprojeto de lei para os trabalhadores-favelados (Coleção DPS/APERJ, Código no 1046). Seguindo a mesma retórica trabalhista ${ }^{10}$ da época, o preâmbulo desse anteprojeto exigia que os direitos dos trabalhadores fossem também estendidos aos "cidadãos-trabalhadores" das favelas:

Considerando que a população das favelas é composta na sua quase totalidade de trabalhadores, e que é dever do Estado, por disposição Constitucional, zelar pelo bem estar da classe obreira e de sua família, no interesse mesmo de melhorar a produtividade do trabalhador e em consequência os índices de produção do país.

Esse preâmbulo previa também a permissão para que os favelados melhorassem progressivamente suas casas com seus próprios recursos, a proteção do pequeno comércio local e o abandono definitivo de qualquer política de remoção dos favelados. 0 artigo $2^{\circ}$ tinha por objetivo eliminar as práticas clientelistas, obrigando os poderes públicos a executar uma série de intervenções no conjunto das favelas. 0 anteprojeto previa também não apenas a desapropriação pela Prefeitura dos terrenos ocupados pelas favelas, para oferecê-los aos favelados (Artigo 3ํ), como a concessão a estes de financiamentos para que pudessem construir suas casas no local (Artigo 4ํ). Defendia a concessão de subsídios fiscais ao pequeno comércio situado nas favelas (Artigo 5을 e entronizava a UTF como único representante oficial de todos os favelados, à imagem da estrutura sindical. Segundo os artigos 6ํ e 7ํ, a Comissão de Favelas deveria ser extinta, e a UTF considerada de utilidade pública, espécie de extensão do poder público, recebendo, inclusive, subvenções para exercer essa função. ${ }^{11}$

Magarinos Torres foi um ferrenho crítico das violentas e arbitrárias operações policiais nas favelas (Gonçalves, 2013) e das remoções empreendidas pelo governador Carlos Lacerda. A cobertura do Correio da Manhã da remoção da favela Getúlio Vargas na Gávea descreve a tentativa do advogado de bloquear a remoção, afirmando que elementos da Secretaria de Serviços Sociais compravam barracos em várias favelas da cidade para instalar pessoas que, na maioria dos casos, eram funcionários subalternos de repartições do governo estadual (Correio da Manhã, 1964: 2).

\section{Desconstruindo O "MITO": MAGARINOS TORRES E SUAS CONTRADIÇÕES}

H á uma dificuldade em se estabelecer diferenças entre a imaginação mitológica e os fatos históricos, sendo necessário o entendimento do processo de transposição da fronteira entre o factual e o mítico, marcado por parcelas de "espontaneidade criadora" e 
"construção intencional" (Girardet, 1987: 72). No tocante à vida familiar de Magarinos Torres, é interessante ressaltar alguns fatos, como as dificuldades financeiras oriundas de sua atuação e militância (Amoroso, 2015: 130-132), ${ }^{12}$ e o parentesco de sua esposa, Dora Mourão de Magarinos Torres, com o general Olímpio Mourão Filho, um dos principais articuladores do golpe de 1964. Por sua vez, sua cunhada, casada com Hélio Magarinos Torres, era irmã de um dos líderes da UDN e aliado de Carlos Lacerda, Mauro Magalhães. Além de afirmar que essas redes de poder foram usadas no momento do golpe militar para proteger Magarinos Torres, ela chega a afirmar que existia uma convivência amistosa entre o advogado e o general (Depoimento de Maria Helena Magalhães Magarinos Torres, 7/3/2011):

(...) antes de ser preso, ele era muito amigo do Mourão Filho. Mourão passava as noites na casa dele aqui na Usina, jogando xadrez. Eles eram muito amigos e jogavam xadrez sempre, a noite toda. Deu essa confusão, de repente estourou essa revolução toda, e ele pegou o nosso carro, a kombi do meu marido, que não era conhecida assim pela polícia, mas o carro dele era, e saiu pela rua. Ele parava no botequim e ligava para o Mourão e falava: 'Mourão, seu safado, você me deixou numa dessa, jogou comigo a noite toda e nem me falou nada, que bananosa que eu estou'. Ele desligava e saía, e a polícia batia aqui. Passava um pouco, ele estava em outro bairro e dizia: 'Mourão, seu isso, seu aquilo, como você faz uma coisa dessa?' E o Mourão, coitado, também não podia falar. Ele falava: 'Eu não podia falar, Antoine, o que eu podia fazer?' o Antoine era o comunista, o Mourão era do governo.

Há outros elementos da memória familiar sobre o advogado que reforçam sua ligação com seus parentes de posição ideológica contrária (Depoimento de Maria Helena Magalhães Magarinos Torres, 7/3/2011):

(sobre o golpe de 1964): Quando ele soube que já se preparava algum movimento, ele estava a par disso, ele morava em uma casa muito grande, e o terreno dele tinha oito quilômetros de terreno para cima. Ele ia até a Estrada do Cristo, então aquela casa tinha aquele terreno que saía lá em cima naquela estrada. Ele ia levando em um saco, ele levava tijolos, levava cimento. Ele construiu uma coisa qualquer dentro daquela mata. Dizia ele: 'Eu estou fazendo isso aqui porque nós vamos ganhar essa, eu e meus amigos'. O Mauro Magalhães, que era meu irmão, na época era líder da UDN, trabalhava com Carlos Lacerda, e o Antoine dizia: 'Ele vai ser perseguido pelo meu grupo, e a minha turma é muito mais violenta do que eles. Ele vai ser perseguido, o Mourão também vai ser perseguido, eu estou fazendo um esconderijo, eu vou botar eles lá, que ali dentro da mata da minha casa ninguém vai descobrir. Eu vou lá levar comida para eles, então eu estou fazendo essa casa'. Ele mesmo construiu com as mãos dele, levou tijolo e fez um cômodo escondidinho ali, ele sempre dizia: 'Olha, vocês têm sorte que vocês ganharam, se a minha turma ganha era uma violência tal que vocês não escapavam'. 
Deve-se ter em mente que essa abordagem colocada pela família de Magarinos Torres também revela uma visão que contribui para a construção mítica do advogado. Por vezes, há a descrição de uma atuação política exageradamente idealista, sem muitas informações sobre as práticas corriqueiras de conchavos e articulações, como demonstra a pitoresca história da construção de um esconderijo para Olímpio Mourão Filho e Mauro Magalhães no quintal de sua casa, caso a "sua turma saísse vencedora em 1964". Porém, a despeito do maior ou menor grau de afetividade dos laços entre o advogado e seus parentes de ideologia contrária, suscetível às variações e sentidos múltiplos típicos da construção da memória, é inegável que tal relacionamento poderia constituir um elemento de tensão na vida pessoal de Magarinos, bem como em seu convívio familiar.

Se a UTF foi extremamente atuante na defesa dos moradores do Borel, ela também suscitou conflitos e tensões, sobretudo pelo fato de ter assumido muitas das funções de regulação interna da favela. Ao nos debruçarmos sobre o livro de Manoel Gomes, temos indícios para melhor refletir sobre o impacto da atuação da UTF entre os moradores, não apenas do Borel, aliás. Manoel Gomes (1980: 34) chega a colocar a necessidade de "não permissão de construção de novos barracões a elementos desassociados da União - só ela exerceria o poder central nos casos relativos à vida interna dos moradores ali localizados". Tais medidas são descritas por Gomes como uma forma de reforçar a resistência contra as investidas da empresa Borel-Meuron para remover os favelados.

De fato, um dos aspectos da atuação da associação de moradores durante a década de 1950 e parte dos anos 1960, período em que atuou pela UTF, foi a regulação da propriedade e a organização interna do Borel (Amoroso, 2015). Essa questão fica visível no depoimento de antigos moradores (Depoimento de Jacaré, ${ }^{13}$ 6/11/2010):

Quando a gente invadia pra fazer um barraquinho, o presidente dizia que tinha que falar com ele antes. Fui fazer o barraquinho de um amigo meu, aí juntou o pessoal da associação, um tesoureiro e o primo dele e disse que não poderia fazer. Mas eu fiz.

A situação descrita acima levanta a possibilidade de conflitos de interesse movidos pela atuação da União como agente de regulação na favela do Borel. Porém essa situação não existiu apenas no Borel, podendo ser estendida a outras favelas nas quais a UTF atuou junto com Magarinos Torres, entre as quais podemos destacar o Parque União, localizado na região que atualmente se convencionou chamar de Complexo da Maré. A maior ocupação da área foi iniciada a partir de 1959 sob o comando de Magarinos Torres, que coordenou o loteamento e estabeleceu o controle sobre quais indivíduos poderiam se instalar como moradores da favela, podendo ser proprietários de apenas um único terreno, além de defender os 
habitantes de tentativas de remoção. Segundo a memória local, o próprio advogado ordenava a destruição dos barracos que eram construídos sem sua autorização (Vaz, 1994). A influência do advogado sobre o Parque União pode ser vista quando chamou seu loteamento inicial de bairro Desembargador Magarinos Torres, em homenagem a seu pai.

É possível identificar uma série de conflitos internos dentro da diretoria da associação local, um diretório da UTF, que revelam uma representação negativa e bem distante daquela descrita em relação ao Borel. No dia 21 de fevereiro de 1962, foi encaminhada uma denúncia à polícia pedindo a apuração de uma situação de conflitos existente no diretório da "União dos Trabalhadores Favelados do Bairro Desembargador Magarinos Torres". Segundo a denúncia (Fundo Polícia Política/APERJ, pasta 2, dossiê 19, folhas 5 e 6),

Foi presidente dessa associação João Alexandrino da Silva, o qual estaria desservindo os seus companheiros, e, antecipando sua demissão, exonerou-se. (...). Tivemos conhecimento de que Alexandrino tem promovido um ambiente de terror através de porte de arma e de auxílio de seus parentes, que estariam também portando facas e outros instrumentos ofensivos.

Desse modo, dois moradores do Parque, Raquel Souza dos Santos e Albino Manoel dos Santos, teriam sido ameaçado de morte "porque não se submeteram a Alexandrino, que os compelia à assinatura de um papel em branco". Também foram feitas ameaças ao "soldado da PMEG [Polícia Militar do Estado da Guanabara] Alberto Camilo (...), ameaça feita em presença de indivíduos que se diziam policiais". Por último, foi solicitada a presença de Magarinos na delegacia local para a prestação de esclarecimentos: "Esteve presente o Dr. Magarinos Torres Filho, que, à minha sugestão, apresentaria um relatório posterior e dos antecedentes, bem como do aspecto legal e contábil da associação" (Fundo Polícia Política/APERJ, pasta 2, dossiê 19, folhas 5 e 6$)$.

0 nome de João Alexandrino se envolveria em outro caso de contornos mais dramáticos, revelador da disputa de diferentes atores pela implementação de projetos ligados às favelas naquela região. Em 1962, Magarinos Torres se envolveu em duas pendengas judiciais. Na primeira, foi acusado de obter lucros com a exploração ilegal do terreno promovendo a venda de bens da União, além de se envolver no assassinato do operário Eufrásio Severino da Silva, que teria em seu poder fichas fornecidas pelo SERFHA para um levantamento dos moradores da favela, o que teria sido a causa de seu assassinato. 0 segundo inquérito tratava da defesa de Magarinos e da exigência de punição de seus detratores, bem como de uma ação de manutenção de posse do terreno movida contra o SERFHA (Amoroso \& Gonçalves, 2011).

Em seu depoimento, Magarinos Torres chegou a afirmar (Fundo Polícia Política/APERJ, dossiê 12, folha 66): 
que todos os depoentes que figuram neste inquérito, ou foram introduzidos subrepticiamente por aquele João Alexandrino ou foram por atos de violência da polícia, e muitos, inclusive, não moravam sequer no local, como os três signatários da petição que dá origem a este inquérito.

Nosso intento não é averiguar, aqui, a veracidade das informações presentes nesse longo ou intrincado processo, mas entender sua ocorrência dentro do campo de disputas de projetos políticos para as favelas nesse período. Pistas para tal objetivo estão presentes na ação de manutenção de posse comandada por Magarinos. Nela, o advogado faz as seguintes acusações (Fundo Polícia Política/APERJ, pasta 2, dossiê 12, folhas 5 a 8):

Desde princípios de 1961, os possuidores do terreno localizado na Avenida Brasil, 7020 a 7030, vinham sendo ameaçados de esbulho, por intermédio do engenheiro Anísio Silva, usando, para ameaçar, guardas e 'memoranda' de intimação do Departamento Estadual de Estradas de Rodagem, marcando prazo aos possuidores para abandonarem a posse (...). Em relação a este processo de homicídio, que corria sob a honrada vigilância de V. Sa., o governador, avocando-o, entregou-o à delegada de ordem política e social, mandando que o delegado Ventura distorcesse a verdade, de modo a indiciar o advogado que esta assina como mandante do crime, o que aquele delegado prevaricador e desonesto tem feito, por meio de depoimentos que sabe falsos, alguns a ele levados por dois "grileiros", Carlos Gonçalves e Felipe Pinto, contra os quais o ora denunciante tem promovido queixas crimes por atos de esbulho e tentativas de despejo e outros crimes, relativamente à posse dos favelados do Borel e da Favela do Mata-Machado, na Estrada das Furnas. (...) junta-se, também, com o seu inegável prestígio, o arcebispo Hélder Câmara, como presidente da Cruzada São Sebastião, telefonando a diretores de jornais e pedindo-lhes que deem curso às caluniosas notícias que propalam a respeito e mandando que padres deponham caluniosamente nos processos forjados, tudo porque, estando acusado pelo ora denunciante e advogado, de haver-se apropriado, indebitamente, de mais de 20 bilhões de cruzeiros destinados a melhoramento em favelas, por intermédio da dita Cruzada, nada realizando ou aplicando do dinheiro que the doou o presidente Juscelino, durante o seu governo (grifos nossos).

A longa passagem acima serve para ilustrar os principais agentes com que a UTF, personificada na figura de Magarinos Torres, disputava a implementação de suas propostas políticas nas favelas ao longo das décadas de 1950 e 1960. Ao mencionar acusações de desvio de verbas públicas contra Dom Hélder Câmara e "seu inegável prestígio", independentemente de as afirmações serem ou não verídicas, Magarinos voltava sua artilharia contra a Igreja, um dos atores que vinham atuando junto aos moradores das favelas desde o final dos anos 1940, com a criação da Fundação Leão XIII, embora seu alvo direto, nesse caso, fosse a Cruzada São Sebastião. É necessário lembrar que a Fundação Leão XIII foi criada com a intenção, entre outras, de disputar a influência sobre os moradores de favelas com o Partido Comunista, com um 
projeto de controle ideológico que depois foi sendo revertido em uma atuação de manutenção de serviços, como centros sociais, creches e provimento de redes de água (Leeds \& Leeds, 1978 e Rios, 1986). A própria Cruzada São Sebastião surgiu logo após o aparecimento da UTF, em 1956, em um contexto de disputas internas dentro da própria Igreja, com um projeto de promoção da integração a partir do conceito de desenvolvimento comunitário, baseado na interpretação dos habitantes de favelas como agentes promotores de sua própria inserção social (Rios, 1986). A crescente aceitação da UTF entre esse segmento social também foi um dos motivos que levaram ao aparecimento da Cruzada dentro de uma disputa política onde as favelas eram o território a ser conquistado (Gonçalves, 2013).

Ao citar Carlos Lacerda, porém, Magarinos Torres mencionava novos atores em disputa em um contexto político que se inaugurou a partir da criação do Estado da Guanabara em 1960. Lacerda foi o primeiro governador do recém-criado estado, e sua política para as favelas pode ser dividida em dois momentos, tendo como marco divisório o ano de 1962.0 primeiro momento foi caracterizado pela atuação de José Arthur Rios à frente da Coordenação de Serviços Sociais. Rios já era conhecido pela sua atuação nas favelas, sobretudo por ter coordenado a elaboração do famoso estudo SAGMACS. ${ }^{14}$ Após 1962, segundo relato do próprio Jose Arthur Rios (15/05/2011), a pressão do mercado imobiliário conduziu a uma mudança profunda da política estadual em relação às favelas, e a Coordenação de Serviços Sociais se tornou uma secretaria de estado e passou ao comando de Sandra Cavalcanti. ${ }^{15} 0$ governo Carlos Lacerda incorporou as remoções de favelados para os distantes conjuntos habitacionais (Leeds \& Leeds, 1978) como política de estado.

Com isso, podemos perceber que os agentes citados por Magarinos Torres em sua denúncia eram atores com propostas de implementação de projetos políticos para as favelas, além de, no caso de Lacerda, ser um representante do poder público. Ou seja, eram sujeitos políticos concorrentes da UTF, configurando-se um quadro de disputas que envolvia, inclusive, confrontos no campo dos discursos e na elaboração de distintas representações dos adversários políticos. Esse imbróglio demonstra o esforço para garantir posições de poder, e pode ser observado tanto na troca de acusações exemplificada pela acusação de Magarinos Torres no assassinato de Eufrásio Severino da Silva, quanto nas insinuações supracitadas de corrupção evocadas pelo advogado.

É interessante perceber que temos um quadro de disputas entre atores políticos envolvendo as favelas na esfera do Judiciário. Porém há algumas diferenças de interesse nas "batalhas pela terra" (Fischer, 2008) que abrangem o período dos anos 1930 a 1950, uma vez que elas não visavam ao direito à permanência ou a interesses da "indústria da expropriação" (Gonçalves, 2013). Nesse caso, o objeto de disputa era a legitimação para a implementação de projetos de intervenção em favelas por sujeitos políticos concorrentes. 
Com relação aos processos nos quais Magarinos Torres se envolveu, é preciso atentar para outro de seus aspectos: a data de realização, a partir de um acontecimento ocorrido no final de 1961, e cujos desdobramentos jurídicos se estenderam pelo ano de 1962. 0 final da década de 1950 é tido como de decréscimo da influência comunista nas favelas (Gonçalves, 2013). Em 1959, foi criada a Coligação dos Trabalhadores Favelados do Rio de Janeiro (CTFRJ) a partir das articulações obtidas pela UTF com José Gomes Talarico em sua chapa com Magarinos Torres nas eleições de 1958 (Lima, 1989). Nísia Trindade Lima chega a mencionar os embates da coligação com o Serviço Especial de Recuperação das Favelas e Habitações Anti-higiênicas (SERFHA), já sob o comando de José Arthur Rios, e com a Cruzada São Sebastião, ocorridos desde o I Congresso dos Trabalhadores, evento que deu origem à CTFRJ. Ainda segundo Lima (1989: 124): "A interferência de questões partidárias nas atividades da entidade motivou, segundo algumas lideranças do movimento de favelas, o declínio das atividades da CTFRJ e sua posterior substituição pela FAFEG, em 1963".

Desse modo, poderíamos considerar o final dos anos 1950 e início dos anos 1960 como um possível período de declínio das ações da UTF. Porém, diante dos processos em que Magarinos se envolveu no decorrer dos anos 1960, há claros indicadores de uma disputa ativa pelo campo de atuação política para a implementação de propostas em favelas. Precisamos nos questionar sobre o grau desse declínio e sobre uma virtual perda de importância da UTF e de seus diferentes diretórios capitaneados pela CTFRJ.

\section{Conclusão}

O livro de Manoel Gomes (1980: 73) se encerra com menções ao golpe de 1964 como uma punição aos que tinham o "desprendimento em defender os injustiçados trabaIhadores brasileiros". Porém há mais elementos não mencionados na história de Magarinos Torres, como suas candidaturas fracassadas ao Poder Legislativo local no Rio de Janeiro em 1958 e 1960. Magarinos foi também atuante no momento do golpe de 1964, quando foi à Rádio Mayrink Veiga, ainda no $1 \stackrel{0}{0}$ de abril, fazer um comunicado em nome da UTF (Fundo Polícia Política/APERJ, prontuário no 47. 727, folha 22):

Trabalhadores favelados, trago, através da Rádio Mayrink Veiga, a rádio que divulga a palavra de ordem do deputado Leonel Brizola, também a palavra de ordem da União dos Trabalhadores Favelados, reunida esta madrugada e que decidiu o seguinte. (...) seus milhares de associados de todas as favelas do estado da Guanabara, se mantenham com seus rádios sintonizados com a Mayrink Veiga, cumprindo ordens do CGT, permaneçam em suas casas, obedientes à greve geral decretada. Organizem-se em grupos de 11, sob a chefia de um chefe e subchefia de outro trabalhador. 
Homens e mulheres favelados, escolham o comandante geral e o seu substituto e subchefe. Destes grupos de chefe, escolham o comandante geral de cada favela, que deve levar seu mandato à sede da União dos Trabalhadores Favelados, na rua São Miguel, na Tijuca (...) contra os golpistas, contra a ameaça do governador Carlos Lacerda, em luta contra o domínio fascista que não respeita o lar dos trabalhadores favelados (...). As armas chegarão às nossas mãos em defesa do homem que traz o legado da carta de pensamento de Getúlio (...) atentos à Rádio Mayrink Veiga, que ordens partirão daqui, se usar a força, contra a violência do governador fascista.

Desse modo, vemos que o advogado fez um esforço para agregar a UTF aos "grupos dos onze" de Leonel Brizola, ${ }^{16}$ mais uma vez estabelecendo uma série de críticas a Carlos Lacerda, além de atentar para a possibilidade se "se usar a força". Procurou assim articular questões da política nacional com a situação concreta das favelas cariocas.

E, de fato, com o golpe, o advogado caiu na ilegalidade, chegando a passar uma temporada escondido na casa de seu irmão, o médico Hélio Magarinos Torres. Posteriormente, Antoine de Magarinos Torres chegou a se exilar na embaixada da Bolívia, de onde conseguiu visto para entrar nesse país. Porém acabou retornando para o Brasil, mais uma vez para a casa do irmão. Sua cunhada tentou fazê-lo passar incólume por possíveis olhares denunciadores (Depoimento de Maria Helena Magalhães Magarinos Torres, 07/03/2011):

Eu raspei a barba dele, botei tinta clarinha no cabelo dele, botei ele louro, sem barbicha e louro. Ele ficou diferente, com aquele olhos dele grandes e azuis que não escondiam, eu comprei uns rolinhos e fiz permanente, fiz o cabelo dele igual carapinhas, enrolei o cabelo dele todo, ele ficou diferente. Botei ele no carro e disse: 'Vamos passear'. (...) mas não é que quando passou no Borel ele gritou: 'Ei, pessoal! Sou eu, o Margarinos, olha, só estou lá na casa do meu irmão'. Eu disse: 'Antoine, hoje eu vou te matar agora, Antoine, não faça isso'. Ele: 'Olha, é que eu pintei o cabelo. Vocês não tão reconhecendo?' E deu a ficha toda ali pela rua do Borel (risos).

Antoine de Magarinos Torres faleceu no dia 15 de outubro de 1966 de infarto do miocárdio, problema congênito do qual faleceram seus irmãos, todos por volta dos 50 anos, conforme dito por sua família. 0 entendimento de sua atuação política deve atentar para sua figura não apenas como o herói descrito por Manoel Gomes, mas como mais um ator em um campo de disputas no qual a favela assume seu lugar como espaço de implementação de propostas políticas para as classes populares. Assim, é preciso compreender a figura de Antoine de Magarinos Torres não como a de um "santo protetor das favelas", mas como a de um ator pertencente a um projeto político específico, cujos interesses entravam em conflito com outros, e possuidor de contradições inerentes à própria prática política.

Após a sua morte, sua atuação política caiu no esquecimento, em grande medida por causa da repressão da ditadura. A mobilização política, sobretudo em termos jurídicos, ganhou 
outros contornos no contexto da democratização e seria conduzida pelos esforços da Igreja Católica e o serviço jurídico da Pastoral de Favelas. A jornalista Guida Nunes retomou, com informações por vezes contraditórias, a memória de Magarinos. Essa retomada se consolidou com a obra já citada de Manoel Gomes e o trabalho pioneiro sobre a mobilização política nas favelas de Nísia Trindade (1987) em sua dissertação de mestrado. No entanto, Magarinos Torres voltou a cair no esquecimento, e mesmo o reflorescimento de estudos sobre favelas no final da década de 1990 não retomou a biografia do advogado. A reflexão sobre sua influência foi retomada com trabalhos mais recentes (Fischer, 2008; Gonçalves, 2013; Pestana, 2013; Oliveira, 2014 e Amoroso, 2015), marcados todos pelo esforço de trazer a discussão das favelas para uma reflexão histórica mais densa.

\section{NotAS}

1 Favela localizada no tradicional bairro da Tijuca, no Rio de Janeiro, e cujo surgimento data da década de 1910.

2 Criada em 1954 no Borel como instrumento de mobilização contra um processo de despejo sofrido pela favela, a instituição pretendia ser um organismo que congregasse o movimento associativo dos moradores de favelas de forma ampla em todo Rio de Janeiro, tendo sido a primeira iniciativa do gênero. A UTF tinha como bandeira a luta pela infraestrutura urbana dessas áreas e pelo acesso a direitos diversos para seus moradores. Para um debate mais aprofundado sobre o tema, ver Lima (1989), Fischer (2008), Gonçalves (2013) e Amoroso (2015).

3 Existem estudos que abordam a questão das memórias das favelas desde a virada dos anos 1970 para os anos 1980, devendo-se fazer menção ao pioneirismo do trabalho de Lygia Segala $(1983,1991)$ na favela da Rocinha. Nos anos de 1990 e 2000, vemos um novo florescimento de trabalhos e pesquisas sobre memórias em favelas, como a coletânea de depoimentos de moradores e lideranças organizada por Dulce Pandolfi e Mário Grynszpan (2002) e projetos organizados por uma rede de múltiplos envolvidos, como diferentes lideranças e instituições da sociedade civil e do Terceiro Setor, em favelas como o Borel, Morro da Providência, Morro dos Prazeres, Mangueira e algumas das favelas da Maré, além de iniciativas como o website "Favela tem memória" da ONG Viva Rio. Esses projetos tiveram um momento de culminância em um seminário organizado pelo Instituto Superior de Estudos da Religião (ISER) em 2003, em que a temática foi debatida por esses diferentes sujeitos, com forte participação da academia. Para um breve debate, ver Amoroso (2015). Atualmente algumas dessas iniciativas ainda persistem, mas o quadro geral é de encerramento ou congelamento de atividades.

4 Antigo morador do Borel e militante pecebista já falecido, Manoel Gomes teve ampla atuação na UTF e em várias ocasiões fez parte de sua diretoria. É autor de um livro de memórias sobre o movimento associativo desse morro, cujo processo de elaboração, significado e impacto são abordados de forma mais aprofundada por Amoroso (2015).

5 No entanto, é preciso esclarecer que essa visão sobre a figura e a atuação do advogado, apesar de sua grande preponderância atual no Borel, não é a única historicamente presente nessa favela. Através de pesquisa documental da época é possível notar as diferenças internas entre grupos de distintos interesses, alguns consideravelmente críticos, inclusive, à atuação de Magarinos Torres dentro da UTF e em outras favelas e às atividades do grupo do próprio Manoel Gomes. É interessante citar um caso no qual Magarinos Torres, durante sua clandestinidade, chegou a ter sua presença denunciada nas proximidades do Borel por um morador 
do Morro da Formiga, favela próxima à primeira (Amoroso, 2015: 147). Assim, a memória do autor de "As lutas do povo do Borel" sobre Magarinos e sua atuação deve ser vista como a de um grupo específico que, a partir das dinâmicas internas e próprias de disputa política, conseguiu que seu discurso memorialístico se sobrelevasse localmente sobre outros. Para uma visão mais aprofundada da questão, ver Amoroso (2015).

6 Segundo reportagens dos jornais O Globo, de 23/10/1953, e Correio da Manhã, de 25/10/1953, Magarinos Torres foi membro da comissão organizadora e delegado brasileiro na conferência continental dos Juristas Democráticos, que se realizou na Guatemala em 1952.

7 Uma das mais antigas favelas do Rio de Janeiro, ao que tudo indica ocupada por ex-militares que combateram no levante de Canudos no final do século XIX, a Favela de Santo Antônio localizava-se na área central da cidade, e sua erradicação ocorreu entre as décadas de 1950 e 1960, sendo que grande parte do material arenoso oriundo de sua demolição, uma vez que o morro também foi erradicado, foi utilizado na construção do Aterro do Flamengo. Em 1954, Magarinos Torres levou moradores dessa favela à Câmara dos Vereadores para cobrar solução perante a ameaça de despejo (APERJ, Fundo DPS, no 1046).

80 jornal Imprensa Popular, criado em 1948 e fechado em 1958, era vinculado ao Partido Comunista Brasileiro (PCB). Sucedeu ao jornal Tribuna Popular, fechado em dezembro de 1947. Com a cassação do registro do PCB naquele ano, "tornou-se necessário criar um novo órgão de imprensa que preenchesse as mesmas funções do primeiro: ou seja, um órgão que funcionasse como um jornal de massa, apresentando formulações mais amplas do que o jornal oficial do partido". Para maiores informações, ver http://www.fgv.br/cpdoc/ acervo/dicionarios/verbete-tematico/imprensa-popular. Acesso em setembro de 2016.

9 Os métodos empregados pela UTF, e principalmente por seu fundador, foram constantemente criticados. Segundo o Relatório SAGMACS (Sociedade de Análises Gráficas e Mecanográficas Aplicadas aos Complexos Sociais, 1960:31), famoso estudo sobre o qual serão dados maiores detalhes posteriormente, a UTF queimava as casas de todos os moradores que não pagassem a contribuição obrigatória à associação e também coagia mulheres e crianças a participar das manifestações. Essa visão mostra outra forma de ver a atuação da entidade e de Magarinos Torres, e é fundamental para entender as disputas sobre as favelas e projetos de cidade no período.

10 Deve-se fazer menção ao debate historiográfico acerca das categorias "populismo" e "trabalhismo". A primeira foi elaborada entre os anos 1950 e 1960 a partir do trabalho de intelectuais como Alberto Guerreiro Ramos, Hélio Jaguaribe e Francisco Weffort, entre outros. Categoriza uma política de massas voltada para trabalhadores entendidos como sujeitos passíveis de manipulação em troca de capital eleitoral. A segunda foi elaborada a partir dos anos 1980, a partir de pesquisas de autores como Ângela de Castro Gomes, Lucília de Almeida Neves, Argelina Figueiredo, entre outros. Sua interpretação vê os trabalhadores como um sujeito social dotado de autonomia e capacidade de realização de escolhas políticas de acordo com cálculos conjunturais. Deve-se deixar claro que o debate é extremamente mais complexo e rico que este breve resumo, e a questão do trabalho e dos trabalhadores é abordada por autores de diferentes tendências interpretativas e posições, como Marcelo Badaró Mattos e, mais recentemente, Paulo Fontes e Alexandre Fortes. Para um aprofundamento no histórico do debate entre as duas categorias citadas, ver Ferreira (2001).

11 A Comissão de Favelas foi criada em 1952 e era diretamente ligada ao gabinete do prefeito. Tinha 0 objetivo de coordenar as diversas políticas municipais em relação às favelas e existiu até 1956, quando foi substituída pelo SERFHA (Serviço Especial de Recuperação de Favelas e Habitações Anti-higiênicas). Sobre a comissão, ver Gonçalves (2013) e Oliveira (2014).

12 Essa questão também foi relatada pela sua filha, Rosa Magarinos Torres, no documentário Magarinos, o advogado do Morro (filme de Rafael Soares Gonçalves e Mauro Amoroso e dirigido por Ludmila Curi). 
Segundo sua filha, já no final de sua vida não conseguia mais exercer a advocacia e terminou por vender o escritório e a família vivia dos recursos da venda.

13 Nascido em 1931, o depoente já falecido residiu no Borel a partir de 1954.

14 A SAGMACS foi originalmente criada em São Paulo em 1947 pelo frei dominicano francês Louis-Joseph Lebret. 0 diretor de seu escritório no Rio de Janeiro foi o sociólogo José Arthur Rios, que coordenou um aprofundado estudo sobre as favelas cariocas, inédito em termos de alcance e complexidade. 0 estudo foi publicado pelo jornal O Estado de S. Paulo em dois suplementos especiais em 1960, e no mesmo ano A Tribuna da Imprensa reeditou o trabalho em fascículos. Embora seu título fosse "Aspectos humanos das favelas cariocas", o estudo também passou a ser amplamente conhecido como "Relatório SAGMACS", e é uma das principais fontes da época para o estudo desse tipo de habitação popular. Para um debate aprofundado, ver Mello, Machado da Silva, Freire \& Simões, 2012.

15 Foi a primeira presidente do Banco Nacional de Habitação (BNH) e concorreu às eleições para o governo do estado do Rio de Janeiro em 1982.

16 Movimento criado por Leonel Brizola em outubro de 1963 para militar em prol das reformas de base. Sua denominação vem de sua organização em grupos de 11 pessoas, das quais uma era líder. Após o golpe de 1964, o movimento foi abandonado.

\section{REFERÊNCIAS BIBLIOGRÁFICAS}

AMOROSO, Mauro. Caminhos do lembrar: a construção e os usos políticos da memória no Morro do Borel. Rio de Janeiro: Ponteio, 2015.

\& GONÇALVES, Rafael Soares. Memória hagiográfica e movimentos sociais urbanos: a militância política de Antoine de Magarinos Torres nas favelas cariocas. In: Encontro Regional Sudeste de História Oral, 11, 2011. Anais. São Paulo: ABHO, 2011. 1 CD-ROM.

BOURDIEU, Pierre. A ilusão biográfica. In: FERREIRA, Marieta de Moraes \& AMADO, Janaína (orgs). Usos e abusos da História Oral. Rio de Janeiro, Ed. FGV, 1996.

BRUM, Mario. Cidade alta: história, memória e estigma de favela num conjunto habitacional do Rio de Janeiro. Rio de Janeiro: Ponteio, 2012.

CORREIO DA MANHÃ. "Advogado preso na mudança da favela", 18/3/1964.

COUTINHO, N. Um ensaio de aplicação das técnicas de organização social de comunidade num projeto piloto de conjunto residencial para ex-favelados. Rio de Janeiro: SESC, 1959.

FINLEY, Moses I. Mito, memória e história. In: Uso e abuso da história. São Paulo: Martins Fontes, 1989.

FISCHER, Brodwyn. A poverty of rights: citizenship and inequality in twientieth century Rio de Janeiro. California: Stanford, 2008.

FONTES, Paulo. Trabalhadores e associativismo urbano no governo Jânio Quadros em São Paulo (1953-1954). Revista Brasileira de História, São Paulo, v. 33, 2013.

GIRARDET, Raoul. Mitos e mitologias políticas. São Paulo: Companhia das Letras, 1987.

GOMES, Manoel. As lutas do povo do Borel. Rio de janeiro: Edições Muro, 1980.

GONÇALVES, Rafael Soares. As favelas do Rio de Janeiro: História e Direito. Rio de Janeiro: PALLAS, 2013. 
LEEDS, Anthony \& LEEDS, Elizabeth. A sociologia do Brasil Urbano. Rio de Janeiro: Jorge Zahar Ed., 1978.

LIMA, Nísia Trindade Verônica. O movimento de favelados do Rio de Janeiro: políticas do Estado e lutas sociais. Dissertação (Mestrado em Sociologia) -IUPERJ/UCAM. Rio de Janeiro, 1989.

MELLO, Marco Antonio da Silva; MACHADO DA SILVA, Luiz Antonio; FREIRE, Letícia de Luna \& SIMÕES, Soraya Silveira (orgs). Favelas cariocas: ontem e hoje. Rio de Janeiro: Garamond, 2012.

NEGRO, A. L \& SILVA, F. T. da. Trabalhadores, sindicatos e política (1945-1964). In: DELGADO, Lucilia de Almeida Neves \& FERREIRA, Jorge (org.). Brasil Republicano - o tempo da experiência democrática: da democratização de 1945 ao golpe civil-militar de 1964. Rio de Janeiro: Civilização Brasileira, 2003.

OLIVEIRA, Samuel. "Trabalhadores favelados": identificação das favelas e movimentos sociais no Rio de Janeiro e em Belo Horizonte. Tese (Doutorado) - Rio de Janeiro: PPGHPBC-CPDOC/FGV, 2014.

PANDOLFI, Dulce \& GRYNSZPAN, Mário. Favelas e poder público: uma relação delicada. In: OLIVEIRA, Lúcia Lippi (org.) Cidade: história e desafios. Rio de Janeiro: Ed. FGV, 2002.

__ \&__ (orgs). A favela fala: depoimentos ao CPDOC. Rio de Janeiro: Ed. FGV, 2003.

PESTANA, Marco. A União dos Trabalhadores Favelados e a luta contra o controle negociado das favelas cariocas, 1954-1964. Dissertação (Mestrado em História) - UFF. Niterói, 2013.

RIBEIRO, Jayme Fernandes. "A "paz vermelha": a imprensa comunista brasileira e a "campanha por um pacto de paz". In: Encontro Regional de História, 12, 2006. Anais... Rio de Janeiro: ANPUH-RJ, 2006.

RIOS, Rute. Amando de modo especial os menos favorecidos, 1945-1954. In: VALLA, Victor (org.). Educação e favela: políticas para as favelas do Rio de Janeiro, 1940-1985. Petrópolis: Ed. Vozes, 1986.

SEGALA, Ligia. Varal de lembranças: histórias da Rocinha. Rio de Janeiro: Tempo \& Presença/SEC/MEC/FNDE, 1983.

O riscado do balão japonês: identidade social e trabalho comunitário na Rocinha (1977-1982). Dissertação (Mestrado). Rio de Janeiro: PPGAS-Museu Nacional/UFRJ, 1991.

Sociedade de Análises Gráficas e Mecanográficas Aplicada aos Complexos Sociais (SAGMACS). Aspectos humanos da Favela Carioca. O Estado de São Paulo. São Paulo: 13 e 15 de abril de 1960.

VAZ, Lilian. História dos bairros da Maré: espaço, tempo e vida cotidiana nos bairros da Maré. Rio de Janeiro: SR-5/UFRJ/CNPq, 1994.

\section{Depoimentos E FONTES}

Depoimento de Jacaré, 6/11/2010.

Depoimento de Chico da Lapa, 15/2/2011.

Depoimento de Antônio Eugênio de Magarinos Torres, 7/3/2011.

Depoimento de Maria Helena Magalhães Magarinos Torres, 7/3/2011.

Depoimento de José Arthur Rios, 15/5/2011.

COLEÇÃO DPS/APERJ, Código no 1046.

Fundo de Polícia Política da Guanabara/APERJ, prontuário 47. 727.

Fundo Polícia Política/APERJ, pasta 2, dossiês 12 e 19. 